\title{
Functional study of SCCD pathogenic gene UBIAD1 (Review)
}

\author{
JUMIN XIE ${ }^{1,2}$ and LINGXING $\mathrm{LI}^{3,4}$ \\ ${ }^{1}$ Medical School and ${ }^{2}$ Hubei Key Laboratory of Renal Disease Occurrence and Intervention, \\ Hubei Polytechnic University, Huangshi, Hubei 435003; ${ }^{3}$ Department of Cardiovascular Medicine, \\ Tai'an City Central Hospital, Tai'an, Shandong 271000; ${ }^{4}$ School of Medicine, \\ Shandong University, Jinan, Shandong 250012, P.R. China
}

Received February 26, 2021; Accepted June 29, 2021

DOI: $10.3892 / \mathrm{mmr} .2021 .12345$

\begin{abstract}
Schnyder's crystalline corneal dystrophy (SCCD) is a rare autosomal dominant genetic disorder that is characterized by progressive corneal opacity, owing to aberrant accumulation of cholesterol and phospholipids in the cornea. A number of SCCD affected families have been reported in the world since 1924, when it was first described. In 2007, the molecular basis of SCCD was demonstrated to be associated with a tumor suppressor, UbiA prenyltransferase domain-containing 1 (UBIAD1), which was isolated from the bladder mucosa and demonstrated to be involved in vitamin $\mathrm{K}_{2}$ and CoQ10 biosynthesis. This sterol triggers the binding of UBIAD1 to 3-hydroxy-3-methyl-glutaryl coenzyme A reductase (HMGCR) at endoplasmic reticulum (ER) membranes, which is regulated by an intracellular geranylgeranyl diphosphate (GGpp) molecule. The inability of SCCD-associated UBIAD1 to bind GGpp results in the consistent binding of UBIAD1 to HMGCR at ER membranes. This binding leads to HMGCRs being redundant. Therefore, they cannot be degraded through ER-associated degradation to synthesize abundant cholesterol in tissue cells. Excess corneal cholesterol
\end{abstract}

Correspondence to: Dr Jumin Xie, Hubei Key Laboratory of Renal Disease Occurrence and Intervention, Hubei Polytechnic University, 16 Guilin Road, Xialu, Huangshi, Hubei 435003, P.R. China

E-mail: xiejm922@163.com

Dr Lingxing Li, Department of Cardiovascular Medicine, Tai'an City Central Hospital, 29 Longtan Road, Taishan, Tai'an, Shandong 271000, P.R. China

E-mail: luckykeyan@163.com

Abbreviations: SCCD, Schnyder's crystalline corneal dystrophy; UBIAD1, UbiA prenyltransferase domain-containing 1; TERE1, transitional epithelial response gene 1; HMGCR, 3-hydroxy-3-methyl-glutaryl coenzyme A reductase; GGpp, geranylgeranyl diphosphate; ROS, reactive oxygen species; ERAD, endoplasmic reticulum-associated degradation

Key words: Schnyder's crystalline corneal dystrophy, UbiA Prenyltransferase Domain Containing 1,3-hydroxy-3-methyl-glutaryl coenzyme A reductase, cholesterol biosynthesis, ER-associated degradation accumulation thus leads to SCCD disease. After decades, the efforts of numerous ophthalmologists and scientists have helped clarify the molecular basis and pathogenesis of SCCD, which has guided the effective diagnosis and treatment of this genetic disorder. However, more studies need to be conducted to understand the pathogenesis of SCCD disease from a genetic basis by studying the defective gene, UBIAD1. Results would guide effective diagnosis and treatment of the inherited eye disease.

\section{Contents}

1. Introduction

2. History and clinical symptoms of SCCD

3. UBIAD1 mutations causing SCCD

4. Subcellular localization and functions of UBIAD1

5. Conclusion

\section{Introduction}

Schnyder's crystalline corneal dystrophy (SCCD; MIM 121800) is a rare autosomal dominant genetic disorder that is characterized by progressive bilateral corneal opacity, owing to abnormal accumulation of cholesterol and phospholipids in the cornea (1). The occurrence is equal in both sexes and progressive opacity in the cornea leads to visual loss and eventually blindness (2). In 1924, French ophthalmologists Van Went and Wibaut first reported eight patients from a family within this pedigree who recorded symptoms of corneal opacity in both eyes (3). The Swiss ophthalmologist Schnyder described the clinical manifestations and genetic characteristics of this eye disease in 1927, 1929 and 1939 (4,5). On the basis of his detailed elucidation, this special corneal disease was named Schnyder's crystalline corneal dystrophy (SCCD) (6). In 2007, Orr et al (7), Weiss et al (8) and Yellore et al (9), for the first time, demonstrated that a potential prenyltransferase, UbiA prenyltransferase domain-containing 1 (UBIAD1), was the causal gene responsible for SCCD, independently. Weiss et al and Yellore et al also confirmed that the loci of UBIAD1 associated with SCCD were located on chromosome short arm 1, region $36(8,9)$. After decades, the pathogenesis of SCCD was finally elucidated and linked to the UBIAD1 gene. 
UBIAD1, also known as transitional epithelial response gene 1 (TERE1), was obtained through reverse transcription from the human bladder mucosal extracted RNA. This cDNA fragment was novel and different from the existing full-length gene. Therefore, it was named TERE1. TERE1 is located at the band 6 short arm of region 3 of human chromosome 1 (1p36) and expresses two transcripts ( 1.5 and $3.5 \mathrm{~kb})$, which are widely present in various human tissues but absent or down-regulated in bladder muscle-invasive cell carcinoma (10). These two transcripts were deposited in NCBI with accession numbers AF117064 and NM_013319. The two transcripts also harbor the same open reading frame and encode the UBIAD1 protein. Additionally, formation of these two transcripts is due to alternative splicing (10). This newly identified TERE1 gene was mapped to chromosome 1 p36.11-p36.33 between the microsatellite markers D1S2667 and D1S434, through loss of heterozygosity studies, by McGarvey et al (11), who also demonstrated a $61 \%$ reduced expression of the TERE1 transcriptome in prostate cancer cells. After expressing TERE1 in prostate cancer cell lines LNCAP and PC-3, the cell proliferation rate was reduced by $80 \%$, indicating that TERE1 was a potential tumor suppression factor (11).

To further understand the function of TERE1, McGarvey et al (12) then isolated TERE1-interacted protein apolipoprotein E through bacterial two-hybrid assays. Results demonstrated that this gene reduced the p42/44 MAPK phosphorylation level in human 293 cells. In 2007, different teams confirmed the molecular basis of SCCD (7-9). However, the present data are still elusive in the pathogenesis of this rare hereditary eye disease.

Therefore, in this review studies the history and clinical symptoms of SCCD, UBIAD1 mutations causing SCCD and the pathogenesis of SCCD through diligent literature research. The present study also elucidates the critical correlations between SCCD and UBIAD1, to guide treatment and drug development for SCCD.

\section{History and clinical symptoms of SCCD}

History of SCCD. Swiss ophthalmologist Schnyder described the clinical symptoms and inheritance of the rare autosomal dominant corneal opacity disease and named it Schnyder's crystalline corneal dystrophy (SCCD) $(4,5)$. Besides, some scientists also reported similar cases, for instance, Glees et al (1957) (6) and Garner et al (1972) (13). In 1972, Bron et al (14) reported a family with SCCD whose proband was a 47-year-old Caucasian male with two siblings having this eye disease. Bron et al spent 3 years tracking the causes of SCCD in this family. The patients with SCCD in this pedigree had hyperlipidemia disease and the level of their blood cholesterol, triglycerides and phospholipids from tests were higher compared with that in ordinary individuals. Their blood test results were also consistent within 3 years to this period. Bron et al recorded SCCD clinical features in this pedigree, such as the position of crystalline deposits in the cornea, size and shape of crystalline deposits and visual acuity level. Meanwhile, their study summarized reports of SCCD cases from 1924 to 1972 and was supplemented with patients' personal information and blood lipid-testing results. Finally, they concluded that SCCD occurrence correlated with dyslipidemia (14).
Similarly, Michaels (15) reported a disparate SCCD patient in 1974 with normal blood lipid whose crystalline deposits developed from speckles to circular needle-like crystal precipitates within 20 years. Thiel et al (16) also reported a 19-year-old male SCCD patient with inherited type IIA autosomal dominant hyperlipoproteinaemia that developed progressive deteriorated corneal opacity from 1964 to 1976. However Burns et al (17) used ${ }^{14} \mathrm{C}$-cholesterol labeling of blood cholesterol before giving a penetrating keratoplasty surgery to the SCCD patient. At the time of surgery, 11 days later, cholesterol levels in the cornea were much higher compared with those in serum, suggesting that the cornea was an active site for cholesterol absorption and storage in this eye disorder. Ingraham et al (18) corrected the misunderstanding that once SCCD developed, it would never worsen in the cornea. Meanwhile, Ingraham et al reviewed previous studies of SCCD and concluded that only few patients with SCCD accompanied with hyperlipidemia and hypercholesterolemia were at risk of this disease and that these two indicators alone cannot could not be used as a biomarker for SCCD diagnosis.

Similarly, McCarthy et al (19) performed quantitative biochemical analysis on a corneal button obtained from an SCCD patient and found that accumulated corneal lipids are predominantly composed of phospholipids, free cholesterols and cholesterol esters. Those constituents were markedly elevated in the SCCD cornea than in the cadaveric control cornea. Results were: Phospholipid, 23.6 vs. $4.05 \mathrm{mg} / \mathrm{g}$; free cholesterol, 6.99 vs. $0.52 \mathrm{mg} / \mathrm{g}$ and cholesterol ester, 3.16 vs. $0.26 \mathrm{mg} / \mathrm{g}$. The authors concluded that the pathogenesis of SCCD was due to a primary disorder of lipid metabolism in the cornea. Weiss (20) collected 33 SCCD cases in 1987. Only $17(51.5 \%)$ out of these demonstrated crystalline deposits in the cornea. As the name SCCD can mislead ophthalmologists in diagnosis and treatment, Weiss suggested renaming the disease Schnyder corneal dystrophy (SCD).

Clinical symptoms of SCCD. Schnyder crystalline corneal dystrophy (SCCD, MIM 121800) is a rare autosomal dominant inherited eye disease characterized by progressive opacification in the bilateral corneas, caused by the abnormal accumulation of cholesterols and phospholipids (1,21-23). To understand better the visual morbidity and surgical intervention of SCCD, Weiss et al (8) examined 115 cases from 34 affected families in 2007. Patients were divided into three categories on the basis of age for statistical analysis; i) <26 years, ii) 26-39 years and iii) $\geq 40$ years (24). To date, the youngest SCCD patient found has been a 17-month-old and the occurrence age ranged from 2-81 years, with a mean age of 38.8 \pm 20.4 years.

The clinical characteristics include i) early stage ( $\leq 26$ years), crystalline deposits in the center stromal epithelium (Fig. 1A); ii) middle stage (26-39 years), crystalline deposits continue to accumulate and appear to join together, forming a haze (Fig. 1B); and iii) late stage ( $\geq 40$ years), which is accompanied by aging. Here, the degree of crystallization is increasing, which leads to whole corneal opacity and blindness (Fig. 1C). In addition, 4\% patients with SCCD developed Genu valgum $(24,25)$. Patients with SCCD gradually lose their vision as they age, but their visual acuity was restored to normal through surgery before they turned 40 years old. When patients with SCCD passed the age of 40, the corneal 
A

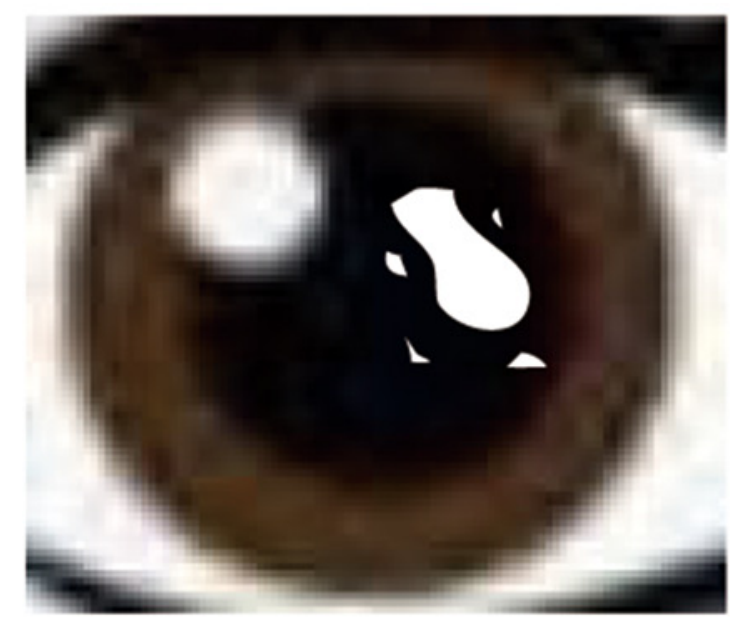

B

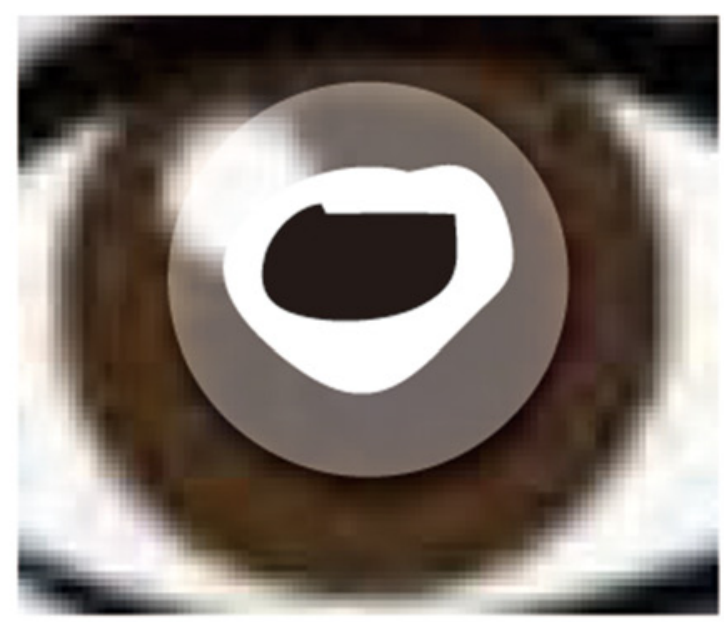

C

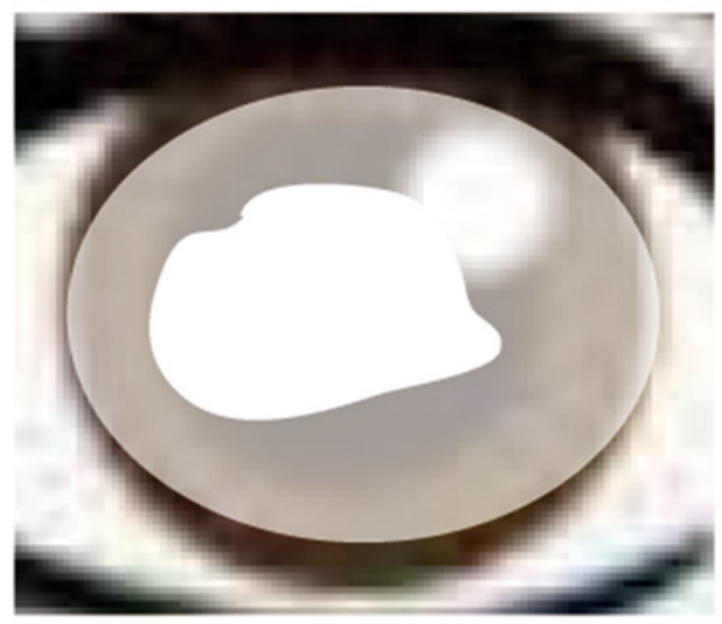

Figure 1. Cartoon illustration of different stages of SCCD. (A) Early stage ( $\leq 26$ years old), crystalline deposits in the center stromal epithelium. (B) Middle stage (26-39 years old), crystalline deposits continue to accumulate and appear to join together, forming a haze. (C) Late stage ( $\geq 40$ years old), the degree of crystallization is increasing, which leads to whole corneal opacity and blindness. Crystalline deposits were labeled with white and the haze is demonstrated in semitransparent circle.

opacity aggravated to final blindness. To date, patients with SCCD have had their vision restored mainly through penetrating keratoplasty and phototherapeutic keratectomy operation $(1,24)$.

\section{UBIAD1 mutations causing SCCD}

UBIADI as the molecular basis of SCCD. The pathogenesis of SCCD remains to be elucidated and requires urgent attention. Innovative methods in molecular genetics have been used in uncovering the pathogenesis of corneal dystrophies (25). The traditional classification in clinics through histopathological and electron-microscopical examinations, which reflects an early disease and immunohistochemical analysis of the deposits, has already aroused a suspicion that is no longer fulfilled in dystrophy types (26,27). The BIGH 3 gene point mutation causes granular dystrophy types I and II, as well as lattice dystrophy types I and IIIA (28). Point mutations on the gelsoline gene on chromosome 9 (9q34) result in the lattice dystrophy type II, which is a manifestation of the Meretoja syndrome (28). As well as this mutation, other genes, gene-products and mutations are known as 16q22 for macular dystrophy, 1p36 for SCCD and 20p11.2-q11.2 for congenital hereditary endothelial and Schlichting's posterior polymorphous dystrophies (28). In another study, Riebeling et al (29) reported the case of a 66-year-old woman and her son with SCCD. The woman had type IV hyperlipoproteinemia and hypercholesterolemia, whereas her son had hypercholesterolemia with elevated LDL-cholesterol levels. Microsatellite marker analysis demonstrated that D1S228 within the candidate interval of 1p34.1-p36 led to the observed SCCD. In 1996, Shearman et al (30) narrowed the SCCD locus to the $16 \mathrm{cM}$ interval between D1S2663 and D1S228 microsatellite markers localized on 1p34.1-p36 through haplotype analysis in two large Swede-Finn kindreds in central Massachusetts.

Similarly, Theendakara et al (31) collected 13 families from Finland, Germany, Turkey and the USA to refine candidate intervals correlated with SCCD and they narrowed the putative region to $1.58 \mathrm{Mbp}$ through identity-by-state analysis. To further identify the genetic basis of SCCD, mutation screening was used to analyze the 15 candidate genes (CORT, CLSTN1, CTNNBIP1, DFFA, ENO1, GPR157, H6PD, KIF1B, LOC440559, LZIC, MGC4399, PEX14, PGD, PIK3CD and $S S B 1)$, which were localized at putative regions in members of the two pedigrees affected with SCCD (32). Though none of these 15 genes were linked to SCCD, Aldave et al (32) reduced the remaining positional candidate genes by half and led to the identification of the genetic basis of SCCD.

Orr et al (7) also confirmed the genetic basis of SCCD, through intensive fine mapping in a large multigenerational family in Nova Scotia, to UBIAD1, which encodes a potential prenyltransferase and is involved in intracellular cholesterol metabolism. Furthermore, Weiss et al (8) analyzed DNA samples in six SCCD-affected families and uncovered that, of these six families, five possessed N102S mutations in UBIAD1 and one family had a G177R mutation in the UBIAD1 gene. Thus, the molecular basis of SCCD was clarified and linked to UBIAD1, which participates in cholesterol synthesis and storage intracellular. After years of efforts by generations of scientists and ophthalmologists, the genetic basis of SCCD was elucidated. Their work, therefore, provided molecular targets and references for SCCD treatment and drug development for this disease.

UBIAD1 mutations causing SCCD. It is 80 years since the initial description of SCCD by French ophthalmologists Van Went and 
Table I. Point mutations of UBIAD1 causing SCCD ("marks hot spot).

\begin{tabular}{|c|c|c|c|c|}
\hline Author(s) (year) & Number & Site & Type & (Refs.) \\
\hline Orr et al (2007) & 1 & 75 & Ser-Phe & (7) \\
\hline Nickerson et al (2010), Evans et al (2018) & 2 & 97 & Ala-Thr & $(36,87)$ \\
\hline Jing et al (2009) & 3 & 98 & Gly-Ser & $(39)$ \\
\hline $\begin{array}{l}\text { Orr et al (2007), Weiss et al (2007), Yellore et al (2007), } \\
\text { Riebeling et al (2003), Nickerson et al (2013), Al-Ghadeer et al (2011), } \\
\text { Du et al (2011), Nickerson et al (2010), Weiss et al (2010), } \\
\text { Meha et al (2009), Evans et al (2018) }\end{array}$ & 4 & $102^{*}$ & Asn-Ser & $\begin{array}{l}(7,8,9,29,33 \\
34,35-38,87)\end{array}$ \\
\hline Handa et al (2020), Evans et al (2018) & 5 & 103 & Thr-Ile & $(83,87)$ \\
\hline Orr et al (2007) & 6 & 112 & Asp-Gly & (7) \\
\hline Nickerson et al (2013), Nickerson et al (2010), Sarosiak et al (2018) & 7 & 112 & Asp-Asn & $(33,36,84)$ \\
\hline Riebeling et al (2003) & 8 & 118 & Asp-Gly & (29) \\
\hline Orr et al (2007), Yellore et al (2007) & 9 & 119 & Arg-Gly & $(7,9)$ \\
\hline Kitazawa et al (2018) & 10 & 120 & Thr-Arg & $(85)$ \\
\hline $\begin{array}{l}\text { Yellore et al (2007), Riebeling et al (2003), Al-Ghadeer et al (2011), } \\
\text { Evans et al (2018) }\end{array}$ & 11 & 121 & Leu-Phe & $(9,29,34,87)$ \\
\hline Nickerson et al (2010) & 12 & 121 & Leu-Val & (36) \\
\hline Nickerson et al (2010) & 13 & 122 & Val-Glu & (36) \\
\hline Nickerson et al (2010) & 14 & 122 & Val-Gly & $(36)$ \\
\hline Riebeling et al (2003), Nickerson et al (2010), Meha et al (2009) & 15 & 171 & Ser-Pro & $(29,36,38)$ \\
\hline Riebeling et al (2003), Nickerson et al (2010) & 16 & 174 & Tyr-Cys & $(29,36)$ \\
\hline $\begin{array}{l}\text { Orr et al (2007), Weiss et al (2007), Riebeling et al (2003), } \\
\text { Nickerson et al (2010) }\end{array}$ & 17 & 175 & Thr-Ile & $(7,8,29,36)$ \\
\hline Evans et al (2018) & 18 & 176 & Gly-Glu & (87) \\
\hline Weiss et al (2007), Nickerson et al (2010) & 19 & 177 & Gly-Arg & $(8,36)$ \\
\hline Nickerson et al (2013), Kitazawa et al (2018) & 20 & 177 & Gly-Glu & $(33,85)$ \\
\hline Riebeling et al (2003) & 21 & 181 & Lys-Arg & (29) \\
\hline Riebeling et al (2003) & 22 & 186 & Gly-Arg & (29) \\
\hline Nickerson et al (2010) & 23 & 188 & Leu-His & $(36)$ \\
\hline Dudakova et al (2019) & 24 & 190 & Ile-Thr & $(2)$ \\
\hline Orr et al (2007), Nickerson et al (2010) & 25 & 232 & Asn-ser & $(7,36)$ \\
\hline Riebeling et al (2003), Nickerson et al (2010) & 26 & 233 & Asn-His & $(29,36)$ \\
\hline Weiss et al (2007), Riebeling et al (2003), Nickerson et al (2010) & 27 & 236 & Asp-Glu & $(8,29,36)$ \\
\hline Weiss et al (2010) & 28 & 240 & Asp-Asn & (37) \\
\hline
\end{tabular}

Wibaut in 1924 (3) and, finally, the molecular basis of SCCD has been correlated with UBIAD1, which is located on chromosome 1 p36 (7-9). Following this, scientists and ophthalmologists across the world continued to report new cases of SCCD.

Increasingly, UBIAD1 point mutations leading to SCCD were also identified (Table I). The present review has investigated 28 point mutations of UBIAD1 that cause SCCD through a literature search and the details are demonstrated in Table I. The mutation hot spot in UBIAD1 was on 102 (N102S), which had been demonstrated in a number of SCCD-affected families (7-9,22,33-38). Similarly, the occurrence of SCCD is higher in European and North American countries compared with other countries and regions associated with this gene defect, including Asia and Africa. Prevalence of SCCD is also reported in the Chinese Han and Japanese populations $(22,36,38,39)$. To further understand this gene, Dong et al (40) constructed an SCCD mouse model with N100S mutation by CRISPR-Cas9 gene editing to further clarify the pathogenesis and treatment of SCCD. The UBIAD1 mutant mouse line that was created carried a mis-sense mutation N100S, corresponding to the human UBIAD1 N102S mutation.

The genetic basis of SCCD has been demonstrated since 2007, but the mechanism of SCCD formation is still elusive. The present study next illustrates the functions of UBIAD1 to build a connection between abnormal lipid metabolism and the pathogenesis of SCCD. 


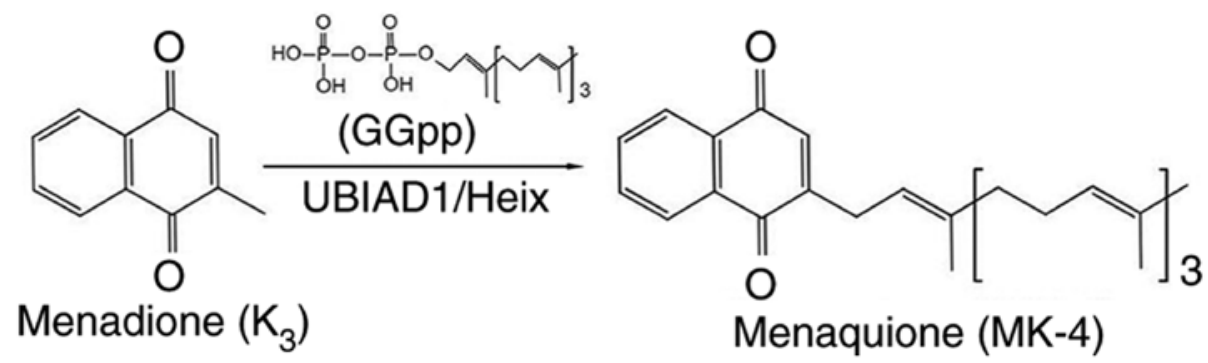

Figure 2. UBIAD1/Heix is a vitamin $\mathrm{K}_{2}$ biosynthesis enzyme. The schematic shows the conversion of menadione to MK-4. UBIAD1, UbiA Prenyltransferase Domain Containing 1; MK-4, menaquinone-4.

\section{Subcellular localization and functions of UBIAD1}

Subcellular localization of UBIAD1. The GFP-UBIAD1 fusion protein vector was transfected into a human osteosarcoma cell line MG-63 to investigate the sub-cellular localization of UBIAD1. The results revealed endoplasmic reticulum (ER) localization, but not Golgi (41). Nickerson et al (36) also confirmed mitochondrial sub-localization of UBAID1, but not ER, in cultured corneal cells. To support their results, immunofluorescence was performed to ensure wild-type and mutated UBIAD1 (N102S) localization in excisional human corneal stromal cells. Similarly, Vos et al (42) reported an orthologous protein of UBIAD1 in Drosophila that was localized in the mitochondria, which supported the result of Nickerson et al (36). Mugoni et al (43) also indicated that UBIAD1was a non-mitochondrial localization prenyltransferases that synthesized CoQ10 in the Golgi. Subsequently, Wang et al (44) demonstrated that RPWS residues of UBAID1 proteins were Golgi retention signal peptides. In mice $\mathrm{N} 2 \mathrm{~A}$ cells, the UBIAD1 protein was also localized in the mitochondria, ER and Golgi (45).

Jiang et al (46) examined the subcellular localization of wild-type UBIAD1 and the SCCD-associated mutants in CHO-K1 cells. They revealed that wild-type UBIAD1 is preferentially localized at Golgi, whereas the SCCD-associated mutants exhibited a diffused distribution and were dominantly sequestered in the ER. Fredericks et al (47) in his study concluded that the UBIAD1 protein was localized in the mitochondria, ER and Golgi apparatus with different functions and exhibited species specificity.

Tumor suppressor. The UBIAD1 is encoded by the UBIADI gene and is involved in significant physiological processes in vivo. A previous study demonstrated that UBIAD1 inhibited cell proliferation of transitional cell carcinoma (10). McGarvey et al (11) transduce exogenous UBIAD1 constructs into two prostate carcinoma cell lines (LNCaP and PC-3), which markedly decrease cell proliferation by $80 \%$. Fredericks et al (48) also demonstrated that UBIAD1 expression decreases in one third of bladder cancer samples through gene microarray analysis. In constructing bladder carcinoma nude-mouse model, UBIAD1 expression was induced, which inhibits tumor occurrence and development. In another study, mutated UBIAD1 did not bind to APOE which causes abnormal cholesterol levels in vivo (12). Elevated cholesterol levels also regulated cancer cell apoptosis and proliferation, thus distorting the balance maintained by intracellular
UBIAD1 (48). Therefore, although UBIAD1 played important roles in bladder tumor suppression, the mechanism remains to be elucidated.

UBIAD1 as a novel CoQ10 and vitamin K2 biosynthetic enzyme. The UBIADl gene encodes a prenyltransferase containing 338 amino acids, with a molecular weight of $36.83 \mathrm{kDa}(7,11)$. Nakagawa et al (41) decreases UBIAD1 expression in human cells using siRNA, which largely suppresses the conversion of deuterium-labeled vitamin $\mathrm{K}$ derivatives to deuterium-labeled menaquinone-4 (MK-4). To establish UBIAD1 function, Nakagawa et al (41) also infected insect cells sf9 with UBIAD1 baculovirus and detected deuterium-labeled MK-4 formed from vitamin K derivatives. Furthermore, Nakagawa et al (41) first identified UBIAD1 as an MK-4 biosynthesis enzyme in humans (Fig. 2), which suggests that vitamin $\mathrm{K}$ did not only existing in plant form, phylloquinone (PK), but also in bacterial form (MK-4).

Heix (Heixuedian), is an orthologous protein of UBIAD1 in Drosophila melanogaster, composed of 359 amino acids with a molecular weight of $39.22 \mathrm{kDa}$ (42). Following Heix mutation, a black dot phenotype lymphoma appeared in the 3rd to 4th instar larvae in Drosophila $(49,50)$. UBIAD1 localizes at the mitochondria and converts vitamin $K_{1}$ to $K_{2}$, which is a significant cofactor in eukaryotic blood coagulation and an electronic carrier binding to the cell membrane in bacteria (43). By contrast, vitamin $K_{2}$ is necessary and sufficient for electron transport in Drosophila mitochondria (42). Therefore, when Heix is mutated, mitochondria dysfunction arise. However, supplementation with vitamin $\mathrm{K}_{2}$ rescues mitochondrial dysfunction (42). Heix is also a dosage-sensitive modifier of pink1, which is mutated in Parkinson's disease, as it affects mitochondrial function. Additionally, Heix converts menadione to vitamin $\mathrm{K}_{2}$ in Drosophila (Fig. 2) (42).

Mugoni et al (43) found that UBIAD1 is a non-mitochondrial localized prenyltransferase and it catalyzed CoQ10 synthesis on the Golgi membrane. Reduced expression of UBIAD1 in vascular cells could decrease antioxidant CoQ10 cytoplasmic content, resulting in reactive oxygen species (ROS)-mediated lipid peroxidation. Similarly, the inhibition of endothelial nitric oxide synthase (eNOS) can prevent UBIAD1-dependent oxidative damage, revealing the crucial role of UBIAD1 and CoQ10 in nitric oxide (NO) signaling and cardiovascular system.

To further broaden UBIAD1 function, Mugoni et al (43) used zebrafish to investigate intracellular roles of the UBIAD1 ortholog gene, Barolo (Bar). The zebrafish cardiovascular 


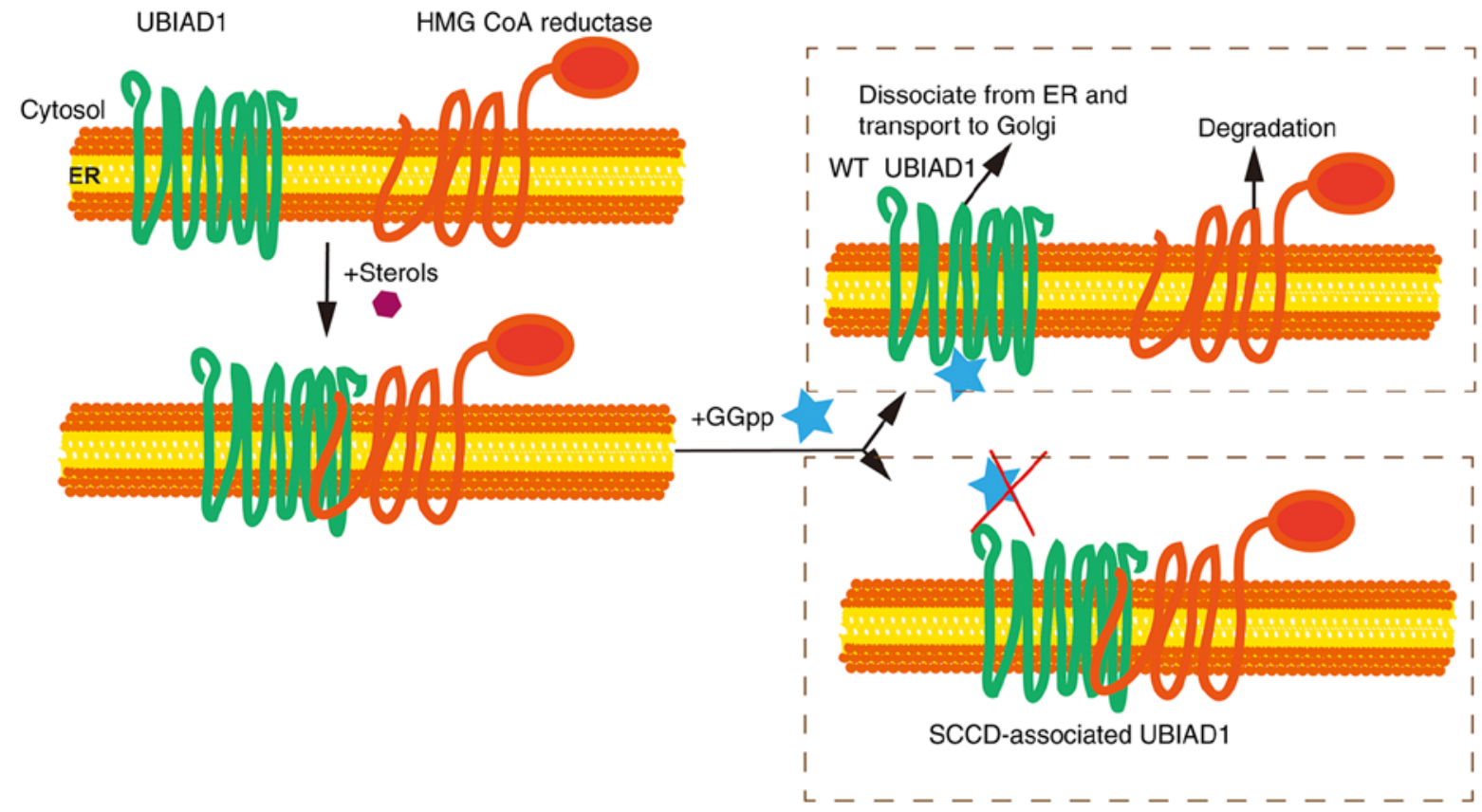

Figure 3. Putative roles of UBIAD1 in sterol-accelerated degradation of HMGCR. In sterol-deprived cells, HMGCR and UBIAD1 localize at ER membrane, independently. The intracellular accumulation of sterols in ER membranes triggers the binding of reductase to UBIAD1. GGpp promotes HMGCR degradation by binding to UBIAD1. UBIAD1 then dissociates from HMGCR in ER membrane and is transferred to the Golgi. The conformation change of mutated UBIAD1 causes SCCD in the cornea and led to the sequestration of HMGCR in the ER membrane. HMGCR retention causes a consistent synthesis of cholesterol in vivo, which leads to excess accumulation of cholesterol in the cornea and finally SCCD. UBIAD1, UbiA Prenyltransferase Domain Containing 1; HMGCR, 3-hydroxy-3-methyl-glutaryl coenzyme A reductase; ER, endoplasmic reticulum; GGpp, geranylgeranyl diphosphate; SCCD, Schnyder's crystalline corneal dystrophy; WT, wild-type.

system fails after Bar is mutated, resulting from oxidative stress and ROS-mediated cell damage. Further study also demonstrated that UBIAD1 is a CoQ10 biosynthesis enzyme localized at the Golgi apparatus, which regulates ROS levels and the redox status in vertebrate cardiovascular system. Therefore, increasing oxidative stress causes heart and vascular cell apoptosis, as well as cardiovascular system failure when UBIAD1 is deficient (43).

Involvement of UBIAD1 in cellular lipid metabolism. When UBAID1 mutates, cholesterols and lipids accumulate abnormally in the cornea, leading to SCCD disease, indicating that UBIAD1 is involved in lipid metabolism in cells $(7-9,16,17,19,46)$. The over-expression of UBIAD1 decreases cholesterol levels in 293 cells and cannot interact with the APOE protein after point mutation, which causes the abnormal metabolism of intracellular cholesterol (48). Fredericks et al $(47,51)$ also constructed a cell line model based on a castration-resistant prostate cancer cell LNCap-C81 to reveal the association between UBIAD1 and steroid synthesis. Intracellular cholesterol synthesis rate, content and correlated enzymes increased when UBIAD1 was deficient. By contrast, the down-regulation of UBIAD1 resulted in mitochondrial damage and considerable cholesterol storage in hepatocellular carcinoma cells, which indicated the crucial role of UBIAD1 in mitochondrial function (52). Preliminary functional studies of UBIAD1 also focused on cell morphology and biochemical parameter change after abnormal expression of UBAID1 (10-12,41,43,48,52).

Schumacher et al (53-55) demonstrated that sterols stimulates UBIAD1 binding to HMG CoA reductase, which is a cholesterol biosynthetic enzyme and subject to sterol-accelerated, endoplasmic reticulum-associated degradation (ERAD) augmented by the non-sterol isoprenoid geranylgeraniol. Geranylgeraniol then inhibits UBIAD1 binding of 3-hydroxy-3-methyl-glutaryl coenzyme A reductase (HMGCR) that promotes reductase degradation and transport of UBIAD1 from the ER to Golgi. This mutation results in a conformation change of mutated UBAID1, thereby inhibiting the binding of GGpp to UBIAD1 mutants, which prevents HMGCR degradation and dissociation of UBIAD1, thus contributing to consistent synthesis and accumulation of cholesterol in vivo (Fig. 3). HMGCR is an important rate-limiting enzyme in the cholesterol and non-sterol isoprenoid biosynthetic pathway, which is regulated by cholesterol feedback. Mevalonic acid is produced through the reduction of HMG CoA, which forms farnesyl pyrophosphate through a series of reactions and is a substrate in the biosynthesis of GGpp and cholesterol (Fig. 4) (56).

The UbiA superfamily of proteins is a collection of transmembrane prenyltransferases that catalyze the biosynthesis of a number of crucial molecules, such as, ubiquinones, menaquinones, plastoquinones, hemes, chlorophylls, vitamin $\mathrm{E}$ and structural lipids (57). These vital compounds serve as electron and proton carriers for cellular respiration and photosynthesis. They also serve as antioxidants to decrease cell damage and as structural components of microbial cell membranes, which indicates that the UbiA superfamily of proteins is involved in significant physiological processes and human diseases (57). Compared with the Golgi localization of wild-type UBIAD1, SCCD-associated mutants are dominantly detained in the ER and compete with insulin-induced gene 1 (INSIG1) for 


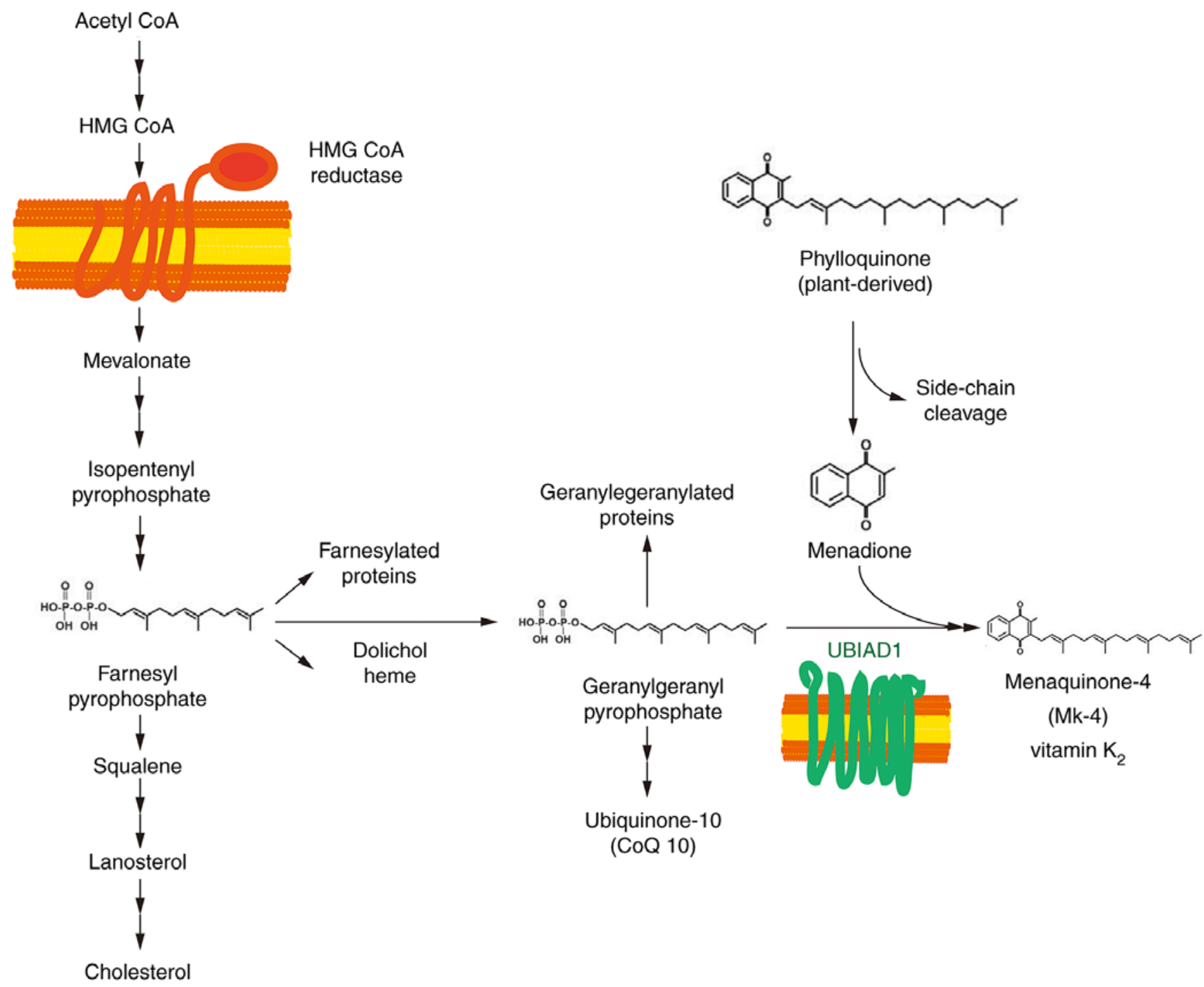

Figure 4. Schematic of cholesterol and Mk-4 biosynthesis in mammalian cells. HMG, 3-hydroxy-3-methyl-glutaryl; Co A, coenzyme A; UBIAD1, UbiA Prenyltransferase Domain Containing 1.

HMGCR binding, hence preventing HMGCR from degradation and increasing the biosynthesis of cholesterol (46). INSIG1 encodes for a probable six trans-membrane domain protein of 277 amino acids. Sterols then induce the ER-anchored INSIG1, which competes with UBIAD1 to bind HMGCR. Also, INSIG1 is associated with E3 ubiquitin ligase, which ubiquitinates HMGCR, eventually leading to the degradation of HMGCR (46).

Jiang et al (46) constructed heterozygous Ubiad1 G184R (Ubiad1 ${ }^{\text {G184R/+}}$ ) knock-in mice that exhibited an elevated expression of HMGCR in various tissues. The aged Ubiadl $1^{G 184 R /+}$ mice, which exhibited identical clinical characteristics with patients with SCCD, demonstrated corneal cholesterol accumulation and opacification. These results indicated that SCCD-associated mutants impede its ER-to-Golgi transport and stabilize its interaction with HMGCR. This disturbed transport then increases cholesterol biosynthesis, causing excess accumulation of cholesterol in the cornea and, eventually, SCCD. Previous studies have demonstrated that GGpp triggers the release of UBIAD1 from HMGCR, allowing ERAD and ER-to-Golgi transport of UBIAD1 (53-55). A
SCCD-related mice model affirms the physiological significance of UBIAD1 in cholesterol homeostasis and demonstrates the inhibition of HMGCR ERAD, contributing to SCCD pathogenesis (46,58). Similarly, Jun et al (59) establishes a biochemical assay for UBIAD1-mediated synthesis of MK-4 in isolated membranes and intact cells. The results reveal that mutated UBIAD1 exhibited reduced Mk-4 biosynthetic activity compared with wild-type UBIAD1.

Sequestration in the ER, therefore, protects SCCDassociated UBIAD1 from autophagy and allows intracellular accumulation of the mutated protein, which magnifies the inhibition of HMGCR ERAD. The results of Jun et al (59) further broaden the understanding of SCCD pathogenesis and limit the efficacy of cholesterol-lowering statin therapies.

\section{Conclusion}

Mutations in UBIAD1, which synthesizes vitamin $\mathrm{K}_{2}$ (subtype menaquinone-4, MK-4) and CoQ10, account for the rare autosomal dominant genetic disorder SCCD, also known as SCD. It also regulates eNOS activity based on its antioxidant 
abilities (36-38). Progressive opaqueness of the cornea, due to the aberrant accumulation of cholesterol, is one of a number of symptoms of SCCD (1,13-25). French ophthalmologists Van Went and Wibaut in 1924 (3) first described SCCD. In the following years, a number of SCCD-affected families were reported across the world (13-18,20,23,28-31,60-86).

The search for the pathogenesis and molecular basis of SCCD lasted for decades until 2007, when three teams uncovered the conundrum due to UBIAD1 mutations (7-9). The pathogenesis of SCCD was then investigated and clarified by consistently exploring the functions of UBIAD1. From research, it was identified that UBIAD1 regulates HMGCR through GGpp in cholesterol biosynthesis and metabolism of significant componential molecules $(46,53,54,56,58,59,87,88)$. UBIAD1 is also a critical tumor suppressor in the urinary system $(11,44,47,48,51,88)$ and regulates cell proliferation through the ras signaling pathway (88). UBIAD1 homologous proteins are widely expressed in bacteria and eukaryotes and play vital roles in different intracellular physiological processes.

The present review clarified the pathogenesis and functions of the SCCD-associated gene UBIAD1, therefore guiding effective diagnosis and treatment of the inherent eye disease.

\section{Acknowledgements}

This review was written to memorialize Professor Ling Hong (Huazhong University of Science and Technology) who died of COVID-19 on 7 February, 2020.

\section{Funding}

This study was supported by the Fund of Hubei Provincial Department of Education (grant no. Q20204508), the Talent Introduction Project of Hubei Polytechnic University (grant no. 19XJK02R) and the Medical and Health Science and Technology Development Program of Shandong Province (grant no. 2019WS208).

\section{Availability of data and materials}

Not applicable.

\section{Authors' contributions}

JX and LL wrote and revised the manuscript. JX critically revised and corrected the manuscript. JX and LL conceived the idea for the review, collected and interpreted the studies included, reviewed the manuscript and contributed significantly to the writing the manuscript. Both authors read and approved the final manuscript. Data authentication is not applicable.

\section{Ethics approval and consent to participate}

Not applicable.

\section{Patient consent for publication}

Not applicable.

\section{Competing interests}

The authors declare that they have no competing interests.

\section{References}

1. Weiss JS: Schnyder corneal dystrophy. Curr Opin Ophthalmol 20: 292-298, 2009.

2. Dudakova L, Skalicka P,Davidson AE and Liskova P: Coincidental occurrence of Schnyder corneal dystrophy and posterior polymorphous corneal dystrophy type 3. Cornea 38: 758-760, 2019.

3. Van Went JM and Wibaut F: A strange inherited corneal alteration. Niederl Tijdschr Geneesk 68: 2996-2997, 1924 (In Dutch).

4. Schnyder WF: Report about a new type of familial corneal disorder. Schweiz Med Wschr 10: 559-571, 1929 (In German).

5. Schnyder WF: Disk-like inherited crytstalline inclusions in the corneal center. KIin Monatsbl Augenheilkd 103: 494-502, 1939 (In German).

6. Glees M: Corneal crystalline dystrophy. Klin Monbl Augenheilkd Augenarztl Fortbild 131: 721-724, 1957 (In German).

7. Orr A, Dubé MP, Marcadier J, Jiang H, Federico A, George S Seamone C, Andrews D, Dubord P, Holland S, et al: Mutations in the UBIAD1 gene, encoding a potential prenyltransferase, are causal for Schnyder crystalline corneal dystrophy. PLoS One 2: e685, 2007.

8. Weiss JS, Kruth HS, Kuivaniemi H, Tromp G, White PS Winters RS, Lisch W, Henn W, Denninger E, Krause M, et al: Mutations in the UBIAD1 gene on chromosome short arm 1, region 36, cause Schnyder crystalline corneal dystrophy. Invest Ophthalmol Vis Sci 48: 5007-5012, 2007.

9. Yellore VS, Khan MA, Bourla N, Rayner SA, Chen MC Sonmez B, Momi RS, Sampat KM, Gorin MB and Aldave AJ: Identification of mutations in UBIAD1 following exclusion of coding mutations in the chromosome 1p36 locus for Schnyder crystalline corneal dystrophy. Mol Vis 13: 1777-1782, 2007.

10. McGarvey TW, Nguyen T, Tomaszewski JE, Monson FC and Malkowicz SB: Isolation and characterization of the TERE1 gene, a gene down-regulated in transitional cell carcinoma of the bladder. Oncogene 20: 1042-1051, 2001.

11. McGarvey TW, Nguyen T, Puthiyaveettil R, Tomaszewski JE and Malkowicz SB: TERE1, a novel gene affecting growth regulation in prostate carcinoma. Prostate 54: 144-155, 2003.

12. McGarvey TW, Nguyen TB and Malkowicz SB: An interaction between apolipoprotein $\mathrm{E}$ and TERE1 with a possible association with bladder tumor formation. J Cell Biochem 95: 419-428, 2005.

13. Garner A and Tripathi RC: Hereditary crystalline stromal dystrophy of Schnyder. II. Histopathology and ultrastructure. $\mathrm{Br}$ J Ophthalmol 56: 400-408, 1972.

14. Bron AJ, Williams HP and Carruthers ME: Hereditary crystalline stromal dystrophy of Schnyder. I. Clinical features of a family with hyperlipoproteinaemia. Br J Ophthalmol 56: 383-399, 1972

15. Michaels RG: Corneal crystalline dystrophy of Schnyder. Arch Ophthalmol 92: 64-65, 1974.

16. Thiel HJ, Voigt GJ and Parwaresch MR: Crystalline corneal dystrophy (Schnyder) in the presence of familial type IIa hyperlipoproteinaemia (author's transl). Klin Monbl Augenheilkd 171: 678-684, 1977 (In German).

17. Burns RP, Connor W and Gipson I: Cholesterol turnover in hereditary crystalline corneal dystrophy of Schnyder. Trans Am Ophthalmol Soc 76: 184-196, 1978.

18. Ingraham HJ, Perry HD, Donnenfeld ED and Donaldson DD: Progressive Schnyder's corneal dystrophy. Ophthalmology 100: 1824-1827, 1993.

19. McCarthy M, Innis S, Dubord P and White V: Panstromal Schnyder corneal dystrophy. A clinical pathologic report with quantitative analysis of corneal lipid composition. Ophthalmology 101: 895-901, 1994.

20. Weiss JS: Schnyder crystalline dystrophy sine crystals. Recommendation for a revision of nomenclature. Ophthalmology 103: 465-473, 1996.

21. Weiss JS: More on Schnyder corneal dystrophy. Ophthalmology 116: 2260, 2009.

22. Weiss JS, Kruth HS, Kuivaniemi H, Tromp G, Karkera J, Mahurkar S, Lisch W, Dupps WJ Jr, White PS, Winters RS, et al: Genetic analysis of 14 families with Schnyder crystalline corneal dystrophy reveals clues to UBIAD1 protein function. Am J Med Genet A 146A: 271-283, 2008. 
23. Lisch W, Weidle EG, Lisch C, Rice T, Beck E and Utermann G: Schnyder's dystrophy. Progression and metabolism. Ophthalmic Paediatr Genet 7: 45-56, 1986.

24. Weiss JS: Visual morbidity in thirty-four families with Schnyder crystalline corneal dystrophy (an American Ophthalmological Society thesis). Trans Am Ophthalmol Soc 105: 616-648, 2007.

25. Jing Y and Wang L: Morphological evaluation of Schnyder's crystalline corneal dystrophy by laser scanning confocal microscopy and fourier-domain optical coherence tomography. Clin Exp Ophthalmol 37: 308-312, 2009.

26. Weiss JS, Møller HU, Lisch W, Kinoshita S, Aldave AJ, Belin MW, Kivelä T, Busin M, Munier FL, Seitz B, et al: The IC3D classification of the corneal dystrophies. Cornea 27 (Suppl 2): S1-S83, 2008 (In English, Spanish).

27. Weiss JS: Corneal dystrophy classification. Ophthalmology 116: 1013-1014, 2009

28. Auw-Hädrich $\mathrm{C}$ and Witschel $\mathrm{H}$ : Corneal dystrophies in the light of modern molecular genetic research. Ophthalmologe 99: 418-426, 2002 (In German).

29. Riebeling P, Polz S, Tost F, Weiss JS, Kuivaniemi $\mathrm{H}$ and Hoeltzenbein M: Schnyder's crystalline corneal dystrophy.Further narrowing of the linkage interval at chromosome 1p34.1-p36? Ophthalmologe 100: 979-983, 2003 (In German).

30. Shearman AM, Hudson TJ, Andresen JM, Wu X, Sohn RL, Haluska F, Housman DE and Weiss JS: The gene for Schnyder's crystalline corneal dystrophy maps to human chromosome 1p34.1-p36. Hum Mol Genet 5: 1667-1672, 1996.

31. Theendakara V, Tromp G, Kuivaniemi H, White PS, Panchal S, Cox J, Winters RS, Riebeling P, Tost F, Hoeltzenbein M, et al: Fine mapping of the Schnyder's crystalline corneal dystrophy locus. Hum Genet 114: 594-600, 2004.

32. Aldave AJ, Rayner SA, Principe AH, Affeldt JA, Katsev D and Yellore VS: Analysis of fifteen positional candidate genes for Schnyder crystalline corneal dystrophy. Mol Vis 11: 713-716, 2005 .

33. Nickerson ML, Bosley AD, Weiss JS, Kostiha BN, Hirota Y, Brandt W, Esposito D, Kinoshita S, Wessjohann L, Morham SG, et al: The UBIAD1 prenyltransferase links menaquinone-4 [corrected] synthesis to cholesterol metabolic enzymes. Hum Mutat 34: 317-329, 2013.

34. Al-Ghadeer H, Mohamed JY and Khan AO: Schnyder corneal dystrophy in a Saudi Arabian family with heterozygous UBIAD1 mutation (p.L121F). Middle East Afr J Ophthalmol 18: 61-64, 2011.

35. Du C, Li Y, Dai L, Gong L and Han C: A mutation in the UBIAD1 gene in a Han Chinese family with Schnyder corneal dystrophy. Mol Vis 17: 2685-2692, 2011

36. Nickerson ML, Kostiha BN, Brandt W, Fredericks W, Xu KP, Yu FS, Gold B, Chodosh J, Goldberg M, Lu DW, et al: UBIADI mutation alters a mitochondrial prenyltransferase to cause Schnyder corneal dystrophy. PLoS One 5: e10760, 2010.

37. Weiss JS, Wiaux C, Yellore V, Raber I, Eagle R, Mequio M and Aldave A: Newly reported p.Asp240Asn mutation in UBIAD1 suggests central discoid corneal dystrophy is a variant of Schnyder corneal dystrophy. Cornea 29: 777-780, 2010.

38. Mehta JS, Vithana EN, Venkataraman D, Venkatraman A Yong VH, Aung T and Tan DT: Surgical management and genetic analysis of a Chinese family with the S171P mutation in the UBIAD1 gene, the gene for Schnyder corneal dystrophy. $\mathrm{Br}$ J Ophthalmol 93: 926-931, 2009.

39. Jing Y, Liu $\mathrm{C}, \mathrm{Xu} \mathrm{J}$ and Wang L: A novel UBIAD1 mutation identified in a Chinese family with Schnyder crystalline corneal dystrophy. Mol Vis 15: 1463-1469, 2009.

40. Dong F, Jin X, Boettler MA, Sciulli H, Abu-Asab M, Del Greco C Wang S, Hu YC, Campos MM, Jackson SN, et al: A mouse model of Schnyder corneal dystrophy with the N100S point mutation. Sci Rep 8: 10219, 2018.

41. Nakagawa K, Hirota Y, Sawada N, Yuge N, Watanabe M, Uchino Y, Okuda N, Shimomura Y, Suhara Y and Okano T: Identification of UBIAD1 as a novel human menaquinone-4 biosynthetic enzyme. Nature 468: 117-121, 2010.

42. Vos M, Esposito G, Edirisinghe JN, Vilain S, Haddad DM Slabbaert JR, Van Meensel S, Schaap O, De Strooper B, Meganathan R, et al: Vitamin K2 is a mitochondrial electron carrier that rescues pink1 deficiency. Science 336: 1306-1310, 2012.

43. Mugoni V, Postel R, Catanzaro V, De Luca E, Turco E, Digilio G, Silengo L, Murphy MP, Medana C, Stainier DY, et al: Ubiad1 is an antioxidant enzyme that regulates eNOS activity by CoQ10 synthesis. Cell 152: 504-518, 2013.
44. Wang X, Wang D, Jing P, Wu Y, Xia Y, Chen M and Hong L: A novel Golgi retention signal RPWS for tumor suppressor UBIAD1. PLoS One 8: e72015, 2013.

45. Huang Y and $\mathrm{Hu} \mathrm{Z}$ : UBIAD1 protects against oxygen-glucose deprivation/reperfusion-induced multiple subcellular organelles injury through PI3K/AKT pathway in N2A cells. J Cell Physiol 233: 7480-7496, 2018

46. Jiang SY, Tang JJ, Xiao X, Qi W, Wu S, Jiang C, Hong J, Xu J, Song BL and Luo J: Schnyder corneal dystrophy-associated UBIAD1 mutations cause corneal cholesterol accumulation by stabilizing HMG-CoA reductase. PLoS Genet 15: e1008289, 2019.

47. Fredericks WJ, Yin H, Lal P, Puthiyaveettil R, Malkowicz SB, Fredericks NJ, Tomaszewski J, Rauscher FJ III and Malkowicz SB: Ectopic expression of the TERE1 (UBIAD1) protein inhibits growth of renal clear cell carcinoma cells: Altered metabolic phenotype associated with reactive oxygen species, nitric oxide and SXR target genes involved in cholesterol and lipid metabolism. Int J Oncol 43: 638-652, 2013.

48. Fredericks WJ, McGarvey T, Wang H, Lal P, Puthiyaveettil R, Tomaszewski J, Sepulveda J, Labelle E, Weiss JS, Nickerson ML, et al: The bladder tumor suppressor protein TERE1 (UBIAD1) modulates cell cholesterol: Implications for tumor progression. DNA Cell Biol 30: 851-864, 2011.

49. Xia Y, Midoun SZ, Xu Z and Hong L: Heixuedian (heix), a potential melanotic tumor suppressor gene, exhibits specific spatial and temporal expression pattern during Drosophila hematopoiesis. Dev Biol 398: 218-230, 2015.

50. Dragh MA, Xu Z, Al-Allak ZS and Hong L: Vitamin K2 prevents lymphoma in Drosophila. Sci Rep 7: 17047, 2017.

51. Fredericks WJ, Sepulveda J, Lai P, Tomaszewski JE, Lin MF, McGarvey T, Rauscher FJ III and Malkowicz SB: The tumor suppressor TERE1 (UBIAD1) prenyltransferase regulates the elevated cholesterol phenotype in castration resistant prostate cancer by controlling a program of ligand dependent SXR target genes. Oncotarget 4: 1075-1092, 2013.

52. Morales CR, Grigoryeva LS, Pan X, Bruno L, Hickson G, Ngo MH, McMaster CR, Samuels ME and Pshezhetsky AV: Mitochondrial damage and cholesterol storage in human hepatocellular carcinoma cells with silencing of UBIAD1 gene expression. Mol Genet Metab Rep 1: 407-411, 2014.

53. Schumacher MM, Jun DJ, Johnson BM and DeBose-Boyd RA: UbiA prenyltransferase domain-containing protein-1 modulates HMG-CoA reductase degradation to coordinate synthesis of sterol and nonsterol isoprenoids. J Biol Chem 293: 312-323, 2018

54. Schumacher MM, Jun DJ, Jo Y, Seemann J and DeBose-Boyd RA Geranylgeranyl-regulated transport of the prenyltransferase UBIAD1 between membranes of the ER and Golgi. J Lipid Res 57: 1286-1299, 2016.

55. Schumacher MM, Elsabrouty R, Seemann J, Jo $Y$ and DeBose-Boyd RA: The prenyltransferase UBIAD1 is the target of geranylgeraniol in degradation of HMG CoA reductase. Elife 4: e05560, 2015.

56. Johnson BM and DeBose-Boyd RA: Underlying mechanisms for sterol-induced ubiquitination and ER-associated degradation of HMG CoA reductase. Semin Cell Dev Biol 81: 121-128, 2018

57. Li W: Bringing bioactive compounds into membranes: The UbiA superfamily of intramembrane aromatic prenyltransferases. Trends Biochem Sci 41: 356-370, 2016.

58. Jo Y, Hamilton JS, Hwang S, Garland K, Smith GA, Su S, Fuentes I, Neelam S, Thompson BM, McDonald JG and DeBose-Boyd RA: Schnyder corneal dystrophy-associated UBIAD1 inhibits ER-associated degradation of HMG CoA reductase in mice. Elife 8: e44396, 2019.

59. Jun DJ, Schumacher MM, Hwang S, Kinch LN, Grishin NV and DeBose-Boyd RA: Schnyder corneal dystrophy-associated UBIAD1 is defective in MK-4 synthesis and resists autophagy-mediated degradation. J Lipid Res 61: 746-757, 2020.

60. Wu CW, Lin PY, Liu YF, Liu TC, Lin MW, Chen WM, Lee FL, Lee SM and Hsu WM: Central corneal mosaic opacities in Schnyder's crystalline dystrophy. Ophthalmology 112: 650-653, 2005 .

61. Köksal M, Kargi S, Gürelik G and Akata F: Phototherapeutic keratectomy in Schnyder crystalline corneal dystrophy. Cornea 23: 311-313, 2004.

62. Paparo LG, Rapuano CJ, Raber IM, Grewal S, Cohen EJ and Laibson PR: Phototherapeutic keratectomy for Schnyder's crystalline corneal dystrophy. Cornea 19: 343-347, 2000.

63. Vesaluoma MH, Linna TU, Sankila EM, Weiss JS and Tervo TM In vivo confocal microscopy of a family with Schnyder crystalline corneal dystrophy. Ophthalmology 106: 944-951, 1999. 
64. Dinh R, Rapuano CJ, Cohen EJ and Laibson PR: Recurrence of corneal dystrophy after excimer laser phototherapeutic keratectomy. Ophthalmology 106: 1490-1497, 1999.

65. Meier U, Anastasi C, Failla F and Simona F: Possibilities of therapeutic photokeratotomy with the excimer laser in treatment of Schnyder crystalline corneal dystrophy. Klin Monbl Augenheilkd 212: 405-406, 1998 (In German).

66. Battisti C, Dotti MT, Malandrini A, Pezzella F, Bardelli AM and Federico A: Schnyder corneal crystalline dystrophy: Description of a new family with evidence of abnormal lipid storage in skin fibroblasts. Am J Med Genet 75: 35-39, 1998.

67. Takeuchi T, Furihata M, Heng HH, Sonobe H and Ohtsuki Y: Chromosomal mapping and expression of the human B120 gene. Gene 213: 189-193, 1998

68. Kohnen T, Pelton RW and Jones DB: Schnyder corneal dystrophy and juvenile, systemic hypercholesteremia. Klin Monbl Augenheilkd 211: 135-137, 1997 (In German).

69. Santo RM, Yamaguchi T, Kanai A, Okisaka S and Nakajima A: Clinical and histopathologic features of corneal dystrophies in Japan. Ophthalmology 102: 557-567, 1995.

70. Chern KC and Meisler DM: Disappearance of crystals in Schnyder's crystalline corneal dystrophy after epithelial erosion. Am J Ophthalmol 120: 802-803, 1995.

71. Weiss JS: Schnyder's dystrophy of the cornea. A swede-finn connection. Cornea 11: 93-101, 1992.

72. Brownstein S, Jackson WB and Onerheim RM: Schnyder's crystalline corneal dystrophy in association with hyperlipoproteinemia: Histopathological and ultrastructural findings. Can J Ophthalmol 26: 273-279, 1991.

73. Rodrigues MM, Kruth HS, Krachmer JH, Vrabec MP and Blanchette-Mackie J: Cholesterol localization in ultrathin frozen sections in Schnyder's corneal crystalline dystrophy. Am J Ophthalmol 110: 513-517, 1990.

74. Freddo TF, Polack FM and Leibowitz HM: Ultrastructural changes in the posterior layers of the cornea in Schnyder's crystalline dystrophy. Cornea 8: 170-177, 1989.

75. Wakita M, Kanai A and Nakajima A: Schnyder crystalline dystrophy. Nippon Ganka Gakkai Zasshi 93: 676-681, 1989 (In Japanese).

76. Kompf J, Ritter H, Lisch W, Weidle EG and Baur MP: Linkage analysis in granular corneal dystrophy (Groenouw I), Schnyder's crystalline corneal dystrophy, and reis-bucklers' corneal dystrophy. Graefes Arch Clin Exp Ophthalmol 227: 538-540, 1989.

77. Rodrigues MM, Kruth HS, Krachmer JH and Willis R: Unesterified cholesterol in Schnyder's corneal crystalline dystrophy. Am J Ophthalmol 104: 157-163, 1987.
78. Roth AM,Ekins MB, Waring GOIII,GuptaLM and RosenblattLS: Oval corneal opacities in beagles. III. Histochemical demonstration of stromal lipids without hyperlipidemia. Invest Ophthalmol Vis Sci 21: 95-106, 1981.

79. Bec P, Arne JL, Secheyron P, Poitevin B and Hemous JD: Schnyder's crystalline dystrophy of the cornea. Bull Soc Ophtalmol Fr 79: 1005-1007, 1979 (In French).

80. Ehlers N and Matthiessen ME: Hereditary crystalline corneal dystrophy of Schnyder. Acta Ophthalmol (Copenh) 51: 316-324, 1973.

81. Delogu A: Contribution to the knowledge of Schnyder's crystalline corneal dystrophy. Ann Ottalmol Clin Ocul 93: 1219-1225, 1967 (In Italian).

82. Modabber M, Darvish-Zargar M, Breton L, Chung DD, Duong H, Aldave AJ and Choremis J: Crystalline keratopathy in post-LASIK ectasia: A case report. Cornea 38: 635-638, 2019.

83. Handa S, Thakur A, Rajneesh D, Kulshrestha A and Gupta A: Schnyder's crystalline corneal dystrophy. QJM 113: 66, 2020.

84. Sarosiak A,Udziela M,Ścieżyńska A,OziębłoD, Wawrzynowska A, Szaflik JP and Ołdak M: Clinical diversity in patients with Schnyder corneal dystrophy-a novel and known UBIAD1 pathogenic variants. Graefes Arch Clin Exp Ophthalmol 256: 2127-2134, 2018.

85. Kitazawa K, Wakimasu K, Kayukawa K, Sugimoto M, Nakai J, Weiss JS, Ueno M, Sotozono C and Kinoshita S: Long-term outcome after penetrating keratoplasty in a pedigree with the G177E mutation in the UBIAD1 gene for Schnyder corneal dystrophy. Cornea 37: 554-559, 2018.

86. Jo Y, Kim SS, Garland K, Fuentes I, DiCarlo LM, Ellis JL, Fu X, Booth SL, Evers BM and DeBose-Boyd RA: Enhanced ER-associated degradation of HMG CoA reductase causes embryonic lethality associated with Ubiad1 deficiency. Elife 9: e54841, 2020.

87. Evans CJ, Dudakova L, Skalicka P, Mahelkova G, Horinek A, Hardcastle AJ, Tuft SJ and Liskova P: Schnyder corneal dystrophy and associated phenotypes caused by novel and recurrent mutations in the UBIAD1 gene. BMC Ophthalmol 18: 250, 2018.

88. Xu Z, Duan F, Lu H, Dragh MA, Xia Y, Liang H and Hong L: UBIAD1 suppresses the proliferation of bladder carcinoma cells by regulating H-Ras intracellular trafficking via interaction with the C-terminal domain of H-Ras. Cell Death Dis 9: 1170, 2018.

This work is licensed under a Creative Commons Attribution-NonCommercial-NoDerivatives 4.0 International (CC BY-NC-ND 4.0) License. 